\title{
Resistência antimicrobiana de amostras de Staphylococcus aureus isoladas de recém-nascidos saudáveis
}

\section{Antimicrobial resistance of Staphylococcus aureus isolates obtained from healthy newborns}

\section{La resistencia a los antibióticos de Staphylococcus aureus aisladas de recién nacidos saludables}

Marcelle Paiano ${ }^{\mathrm{I}}$, João Bedendo ${ }^{\mathrm{II}}$

\author{
I Enfermeira. Mestre em Enfermagem. Professora do Departamento de Enfermagem da Faculdade Ingá - Uningá. Maringá, PR. E-mail: \\ marcellepaiano@hotmail.com. \\ II Enfermeiro. Doutor em Enfermagem. Professor do Departamento de Enfermagem da Universidade Estadual de Maringá. Maringá, PR. E-mail: \\ jbedendo@uem.br.
}

\section{RESUMO}

Staphylococcus aureus oxacilina resistente é um dos principais patógenos associados à etiologia das infecções nosocomiais. Em recém-nascidos, a transmissão de $S$. aureus pode ocorrer durante o parto, mas também por meio de contato com familiares, profissionais da saúde e ambiente. O estudo foi realizado num hospital universitário no período de fevereiro a abril de 2007 e teve como objetivo determinar a freqüência de portadores nasais de $S$. aureus entre recém-nascidos saudáveis, verificar o perfil de susceptibilidade das espécies isoladas frente aos antimicrobianos usualmente empregados na prática clínica e identificar a presença do gene mecA, que codifica a resistência a oxacilina. S. aureus foram isolados em 45 (90\%) dos 50 indivíduos estudados e a resistência à oxacilina, determinada pelo método da Concentração Inibitória Mínima, foi observada em 5 amostras (11,1\%). Destas amostras, em 4 (80\%) foi detectada a presença do gene mecA. Destarte, os profissionais de saúde precisam estar particularmente atentos para a identificação de carreadores de S. aureus; pois estão diretamente envolvidos no cuidado e devem tomar precauções para controlar e prevenir sua disseminação.

Descritores: Staphylococcus aureus; Resistência medicamentosa; Criança.

\section{ABSTRACT}

Oxacillin resistant Staphylococcus aureus is a major pathogen associated with the etiology of nosocomial infections. Transmission of S.aureus may occur in newborns during delivery, however, it can also occur through contact with relatives, healthcare professionals and the environment. This study was carried out in a University hospital from February to April of 2007, in order to investigate the frequency of S.aureus nasal carriers among healthy newborns; the profile of susceptibility of isolated species to the antibiotics usually administered in clinical practice; and to identify the presence of gene which encodes resistance to Oxacillin (mecA gene). Staphylococcus aureus was isolated in 45 $(90 \%)$, out of the 50 subjects investigated. Oxacillin resistance, determined by measuring the Minimum Inhibitory Concentration, was observed in 5 samples $(11.1 \%)$. In 4 of the samples analyzed $(80 \%)$, it was detected the presence of the mecA gene. Therefore, healthcare professionals are advised to take particular attention in order to identify the bearers/carriers of $S$. aureus, since such professionals are directly involved in providing care to patients; thus they must take precautions to control and prevent the germ spread.

Descriptors: Staphylococcus aureus; Drug resistance; Newborns; Children.

\section{RESUMEN}

Staphylococcus aureus oxacilina resistente es uno de los principales patógenos asociados a la etiología de las infecciones nosocomiales. En recién nacidos, la transmisión del $S$. aureus puede darse durante el parto, pero también puede ocurrir por medio del contacto con familiares, profesionales de la salud o por el medio ambiente. El estudio se realizó en un hospital universitario, en el período de febrero a abril de 2007 y tuvo como objetivo determinar la frecuencia de portadores nasales del $S$. aureus entre recién nacidos sanos, comprobar el perfil de susceptibilidad de las especies aisladas frente a los antimicrobianos que se emplean generalmente en la práctica clínica y identificar la presencia del gene mecA, que codifica la resistencia a la oxacilina. Se aislaron S. aureus en 45 ( $90 \%$ ) de los 50 sujetos estudiados y en 5 muestras $(11,1 \%)$ se observó resistencia a la oxacilina, determinada por el método de la Concentración Inhibitoria Mínima. De esas muestras, en 4 de ellas (80\%) se detectó la presencia del gene mec. A. Por lo tanto, es necesario que los profesionales de salud estén particularmente atentos para la identificación de agentes del S. aureus, porque se encuentran directamente involucrados en el cuidado y deben tomar precauciones para controlar y prevenir su diseminación.

Descriptores: Staphylococcus aureus; Resistencia a medicamentos; Niños. 


\section{INTRODUÇÃO}

Estima-se que entre $20 \%$ e $40 \%$ dos adultos são portadores de Staphylococcus aureus, sendo a área mais frequentemente colonizada, o vestíbulo nasal anterior ${ }^{(1)}$. A transmissão cruzada pode ocorrer entre profissionais de um hospital, entre familiares, inclusive entre mãe e filho(2).

Ao nascer, os recém-nascidos podem ser colonizados por Staphylococcus aureus, principalmente no coto umbilical, na área perineal, na pele e, às vezes, no trato gastrointestinal. A transmissão de mãe para filho de $S$. aureus oxacilina resistentes (ORSA) tem sido relatada na literatura, sendo que pode ocorrer por via placentária, bem como por secreções genitais. Além disso, a transmissão através do leite materno, resultando em infecção no recém nascido, também tem sido registrada(3).

A transmissão de ORSA de membros da família para o recém-nascido e prematuro também vem sendo relatada, estudos identificaram uma taxa de mulheres grávidas portadoras, variando entre $0,8 \%$ e $1,3 \%$. O reconhecimento de que as mães podem servir como reservatórios de ORSA implicam em uma nova questão no que se refere à proposição de medidas de controle de infecção hospitalar ${ }^{(4)}$.

Desde os primeiros relatos de ORSA, como um dos principais patógenos nosocomiais dos anos sessenta, a incidência de infecções causada por esse microrganismo continua aumentando, ocasionando aumento do tempo de hospitalização, custos dos serviços de saúde, além de elevação do índice de mortalidade ${ }^{(5)}$.

Pacientes carreadores de ORSA constituem-se em uma base importante para programas de controle de infecção. A identificação do carreador assintomático implica no planejamento e implementação de ações preventivas, incluindo medidas apropriadas de barreira( ${ }^{(6)}$.

A resistência antimicrobiana é um reflexo dos hábitos de uso dos antimicrobianos em cada comunidade e desta forma é importante conhecer o padrão de resistência de cada um dos grupos de pacientes atendidos em cada hospital(7). Monitorar a evolução da resistência de $S$. aureus é importante, pois se trata de um microrganismo que apresenta alta versatilidade em desenvolver resistência aos antimicrobianos e com diferentes matizes de expressão fenotípica a um mesmo antimicrobiano( ${ }^{(8)}$.

Para detecção rotineira da resistência à oxacilina os testes de disco-difusão são os mais largamente utilizados. Entre todas as penicilinas penicilinaseestáveis, a oxacilina é a preferida para testes "in vitro" utilizando disco-difusão e vem sendo utilizada por várias décadas, com estudos mostrando acurácias variadas, provavelmente devido à ocorrência do fenômeno da heterorresistência( ${ }^{(9)}$. Há também testes para determinação da concentração inibitória mínima (CIM) da oxacilina para os estafilococos, incluindo métodos de diluição em ágar e em caldo e de gradiente de difusão em ágar, que possibilitam uma avaliação quantitativa da resistência à oxacilina com maior acurácia(10).

A resistência à oxacilina é variável e depende da expressão do gene $m e c A$, produção de betalactamases e Pbp's modificadas ${ }^{(11)}$, e se caracteriza pelo fato de que uma população bacteriana resistente pode ou não carrear o gene $m e c A$, o que significa que nem todas expressam sua resistência da mesma forma(12).

Considerando o exposto propusemos o presente estudo que tem como objetivo verificar a aquisição nasal de $S$. aureus em recém-nascidos saudáveis e verificar a resistência aos antimicrobianos utilizados na rotina clínica, por meio da determinação da concentração inibitória mínima, teste de disco difusão e deteç̧ão do gene mecA nas amostras isoladas.

\section{MATERIAIS E MÉTODOS}

Este estudo foi desenvolvido no período de fevereiro a abril de 2007 em um Hospital Universitário do Norte do Paraná credenciado junto ao Sistema Único de Saúde. As coletas dos espécimes foram obtidas após consentimento informado por escrito dos responsáveis. O projeto foi aprovado pelo Comitê de Ética da Universidade Estadual de Maringá (Parecer n.o 381/2006) atendendo à resolução 196/96.

Foram coletadas amostras dos vestíbulos nasais de 50 recém-nascidos. Os critérios de inclusão dos RNs foram: ter nascido no referido hospital durante o período de estudo, possuir residência fixa em Maringá-PR e ausência de qualquer sinal ou sintoma clínico de doença após o parto.

Um total de 59 RNs foram elegíveis para o estudo. As amostras dos vestíbulos nasais dos bebes foram coletadas da seguinte forma: 1) $1^{\text {a }}$ coleta - ao nascer no Centro Cirúrgico. Essa amostra era encaminhada ao laboratório de Microbiologia e analisada; caso fosse positiva para S. aureus, era estocada para posteriores testes; se negativa era realizada a segunda coleta. 2) $2^{a}$ coleta - era realizada antes da alta hospitalar, e encaminhada ao laboratório; se positiva era estocada; caso contrário uma terceira coleta era realizada no $15^{\circ}$ dia de vida do RN, em seu domicilio, sendo estocada se apresentasse positividade para $S$. aureus.

O material biológico dos recém-nascidos foi obtido friccionando-se o swab, no terço inferior de cada um dos vestíbulos nasais. No Laboratório de Microbiologia o material foi semeado em placas de Petri $90 \times 15 \mathrm{~mm}$ contendo ágar manitol salgado e incubado por 72 horas a $37^{\circ} \mathrm{C}$. Após a semeadura o swab foi mantido em caldo de soja tripticaseína (TSB) adicionado $\mathrm{NaCl}$ a $2 \%$ e incubado por 24 horas a $37^{\circ} \mathrm{C}$. Após a incubação em caldo, o material foi 
semeado em ágar manitol salgado e incubado a $37^{\circ} \mathrm{C}$ por mais 72 horas.

Duas colônias suspeitas de pertencerem a $S$. aureus foram repicadas para TSB e incubadas por 18 a 24 horas a $37^{\circ} \mathrm{C}$ e em seguida plaqueadas em Agar Mueller Hinton (Becton Dicksinson and Company, BD Diagnostic Systems, USA) para verificação da pureza das colônias.

Colônias puras suspeitas de pertencer a $S$. aureus foram submetidas à coloração de Gram e prova da produção de coagulase em tubo. As colônias que se apresentaram com cocos gram-positivos agrupados em cachos e produtoras de coagulase foram estocadas, em duplicata, em freezer a $-20^{\circ} \mathrm{C}$. Para manutenção das estirpes empregou-se solução de glicerol (ágar/ágar + solução de glicerol a 30\%).

A susceptibilidade das amostras de $S$. aureus a oxacilina foi determinada através do teste de Determinação da Concentração Inibitória Mínima (CIM) pelo método de ágar diluição e pelo método de disco difusão. Para o teste de disco difusão, além da oxacilina, foram utilizados: cefoxitina $30 \mu \mathrm{g}$, vancomicina $30 \mu \mathrm{g}$, gentamicina $10 \mu \mathrm{g}$, telitromicina $15 \mu \mathrm{g}$, tetraciclina $30 \mu \mathrm{g}$, norfloxacina $10 \mu \mathrm{g}$, mupirocina $5 \mu \mathrm{g}$ e linezolide $30 \mu \mathrm{g}$.

Os isolados identificados como resistentes a oxacilina, pelos dois métodos, foram investigados quanto a presença do gene mecA, por meio da técnica de reação em cadeia da polimerase (PCR), segundo metodologia proposta por Vannuffel(13). Os produtos amplificados foram visualizados através de eletroforese em gel de agarose a $2 \%$ corado com Brometo de Étidio. A visualização de um fragmento de 310 pares de base identifica a presença do gene.

\section{RESULTADOS E DISCUSSÃO}

S. aureus é considerado como membro persistente da microbiota endógena humana e relacionado a importantes processos infecciosos. Entre 20 e $70 \%$ da população adulta são portadores de $S$. aureus nas fossas nasais, sendo que em recémnascidos esta porcentagem é expressivamente maior nas primeiras semanas após o nascimento, podendo atingir $100 \%$ nas crianças no quarto dia de vida(14).

Das 50 parturientes estudadas, 29 (58\%) tiveram recém-nascidos do sexo masculino e 21 $(42 \%)$ do sexo feminino. O parto normal prevaleceu em relação ao parto cesárea ( $58 \%$ vs. $42 \%)$. Em relação à faixa etária materna, $18 \%$ das parturientes tinham entre 14 e 19 anos, $64 \%$ entre 20 e 28 anos e $18 \%$ entre 31 e 40 anos. A idade gestacional variou de 34 a 42 semanas, sendo que para $42 \%$ das gestantes a idade gestacional foi de 39 semanas.

Dos 50 recém-nascidos amostrados, em 45 foi isolado $S$. aureus. Na primeira coleta, realizada logo após o nascimento, a positividade para $S$. aureus foi de 24\% (12/50); na segunda coleta, realizada antes da alta hospitalar, a positividade acumulada foi de
$72 \%(36 / 50)$ e na terceira coleta, com 15 dias de nascido, alcançou $90 \%$ (45/50).

O recém-nascido durante a gestação está em ambiente estéril. Ao nascer sofre colonização por germes da flora vaginal materna, e secundariamente por agentes existentes no berçário. A colonização é constituída desta forma pela presença de flora bacteriana na pele e mucosas do recém-nascido(15).

Em se tratando do tipo de parto, observamos que $29(58 \%)$ crianças nasceram por parto normal. Dessas, em $26(89,6 \%)$ foram encontrados $S$. aureus. Em relação aos 21 (42\%) RN nascidos por parto cesárea, 19 (90,5\%) apresentavam o microrganismo.

Observou-se que independente do tipo de parto, quase a totalidade dos RNs, eram carreadores de $S$. aureus. Ao contrario dos RNs nascidos de parto normal, os RNs nascidos de parto cesárea não são expostos a flora vaginal da mãe. Assim, após o nascimento o RN começa a ser colonizado por microrganismos existentes nas mãos dos profissionais de saúde e no ambiente.

Em estudo multicêntrico, onde se avaliou a colonização de $S$. aureus em crianças saudáveis e doentes, de 831 crianças saudáveis investigadas, $23,5 \%$ estavam colonizadas com $S$. aureus. Já dentre as 118 crianças doentes, $36,4 \%$ eram portadoras desse microorganismo. Cinco $(2,6 \%)$ das crianças saudáveis colonizadas eram colonizadas por ORSA em comparação a nove (21\%) das crianças cronicamente doentes. Crianças mais velhas, membros da família e profissionais de saúde foram associados à colonização em crianças saudáveis e somente a idade foi relacionada à colonização nas crianças enfermas(16).

ORSA também tem sido motivo de grande preocupação em neonatologia devido ao seu potencial de disseminação no ambiente hospitalar, como também pela elevada morbidade e mortalidade associada a infecções por esse microorganismo. A prevalência de ORSA isolado de swabs nasais de RN em um hospital maternidade do Rio de Janeiro foi de $47,8 \%$ (43/90). Entre os indivíduos colonizados, $74,4 \%$ apresentavam colonização assintomática. Esses achados sugerem que o trato respiratório seja a porta de entrada para a colonização por ORSA, podendo levar ao desenvolvimento de pneumonias, sepse e morte, evidenciando, assim, a necessidade de monitoramento dos portadores nasais ${ }^{(17)}$.

Neste estudo as amostras de $S$. aureus isoladas de recém-nascidos saudáveis foram, inicialmente, avaliadas quanto à susceptibilidade a oxacilina através de método de determinação da CIM e pelo método de difusão em disco com o uso de alguns antimicrobianos, conforme recomendação do $\mathrm{CLSI}^{(18)}$.

Através da CIM, foi possível detectar cinco recém-nascidos portadores de cepas resistentes a oxacilina. Dentre essas amostras, duas eram culturas 
obtidas após 15 dias do nascimento (CIM de 8 $\mu \mathrm{g} / \mathrm{ml})$, duas eram culturas de 48 horas após 0 nascimento (CIM de $8 \mu \mathrm{g} / \mathrm{ml}$ ) e uma era de cultura logo após o nascimento (CIM de $8 \mu \mathrm{g} / \mathrm{ml}$ ).

É importante ressaltar a positividade ao nascimento, pois, os RN foram positivos ainda no Centro Cirúrgico. Nesse contexto, torna-se importante destacar a detecção de ORSA em várias unidades hospitalares, inclusive no Centro Cirúrgico, onde se acreditava não haver casos. As precauções anti-infecciosas atingem um nível complexo no ambiente do Centro Cirúrgico em virtude do grau de invasibilidade dos procedimentos cirúrgicos e anestésicos, e a consequente diminuição das defesas orgânicas, fazendo com que este momento seja determinante para a ocorrência de infecção hospitalar pós-cirurgia. Isso é preocupante, principalmente pelo fato do Centro Cirúrgico atender clientes sadios e que especialmente os RN tornam-se expostos ao risco de colonizar-se, podendo tal situação ser letal(19).

Das cinco amostras resistentes a oxacilina pelo método da CIM, quando submetidas ao teste de disco difusão (DD) todas se mostraram resistentes para cefoxitina. Ainda pelo método de DD, quando testadas com os antimicrobianos linezolide, vancomicina, mupirocina e telitromicina, as cinco amostras foram sensíveis aos antimicrobianos testados (Tabela 1).

Tabela 1: Resultados do teste de susceptibilidade antimicrobiana das 5 amostras de $S$. aureus dos RNs estudados no período de fevereiro a abril de 2007.

\begin{tabular}{|c|c|c|c|c|c|c|c|c|c|c|}
\hline \multirow{2}{*}{ Perfis de Susceptibilidade } & \multirow{2}{*}{$\operatorname{CIM}(\mu \mathrm{g} / \mathrm{ml})$} & \multirow{2}{*}{$\begin{array}{l}\text { Gene } \\
\text { MecA }\end{array}$} & \multicolumn{8}{|c|}{ Antimicrobianos } \\
\hline & & & CEF & GEN & LIN & VAN & TET & CIP & MUP & TEL \\
\hline Criança $\left(1^{\circ} \mathrm{col}\right)$ & 8 & Sim & $\mathrm{R}$ & $\mathrm{R}$ & $\mathrm{S}$ & $\mathrm{S}$ & $\mathrm{R}$ & $\mathrm{S}$ & $\mathrm{S}$ & $\mathrm{S}$ \\
\hline Criança (20 col) & 8 & Sim & $\mathrm{R}$ & $\mathrm{R}$ & $\mathrm{S}$ & $\mathrm{S}$ & $\mathrm{R}$ & $\mathrm{R}$ & $\mathrm{S}$ & $\mathrm{S}$ \\
\hline Criança (20 col) & 8 & Sim & $\mathrm{R}$ & $\mathrm{R}$ & $\mathrm{S}$ & $\mathrm{S}$ & $\mathrm{R}$ & $\mathrm{R}$ & $\mathrm{S}$ & $\mathrm{S}$ \\
\hline Criança (30 col) & 8 & Não & $\mathrm{R}$ & $\mathrm{S}$ & $\mathrm{S}$ & $\mathrm{S}$ & $\mathrm{S}$ & $\mathrm{S}$ & $\mathrm{S}$ & $\mathrm{S}$ \\
\hline Criança (30 col) & 8 & Sim & $\mathrm{R}$ & $\mathrm{S}$ & $\mathrm{S}$ & $\mathrm{S}$ & $\mathrm{S}$ & $\mathrm{R}$ & $\mathrm{S}$ & $\mathrm{S}$ \\
\hline $\begin{array}{l}\text { Legenda: } \\
\text { - S: sensível; } \\
\text { - R: resistente; } \\
\text { - OXA: oxacilina; }\end{array}$ & $\begin{array}{l} \\
\bullet \\
\bullet \\
\bullet\end{array}$ & $\begin{array}{l}\text { EEF: cefo } \\
\text { GEN: gen } \\
\text { IN: linez } \\
\text { JAN: van }\end{array}$ & $\begin{array}{l}\text { itina; } \\
\text { amicin } \\
\text { lid; } \\
\text { omicin }\end{array}$ & & & $\begin{array}{l} \\
\bullet \\
\bullet \\
\bullet\end{array}$ & $\begin{array}{l}\text { TET: } \\
\text { CIP: } \\
\text { MUP: } \\
\text { TEL: }\end{array}$ & $\begin{array}{l}\text { etracic } \\
\text { proflos } \\
\text { nupiro } \\
\text { elitrom }\end{array}$ & $\begin{array}{l}\text { na; } \\
\text { cina; } \\
\text { ina; } \\
\text { ina. }\end{array}$ & \\
\hline
\end{tabular}

S. aureus que apresentam resistência a oxacilina são, frequentemente, resistentes a outros grupos de agentes antimicrobianos mais comuns como os aminoglicosídeos, macrolideos, cloranfenicol, tetraciclina e fluoroquinolonas, tornando-se um grande risco para o homem e animais em casos de infecções. A identificação de cepas ORSA procedente da comunidade intra-hospitalar ou de pacientes internados tem ocorrido com freqüência cada vez maior, e atualmente um percentual importante dessas cepas também tem sido isolado de indivíduos saudáveis na comunidade. A vigilância epidemiológica neste caso é importante em função da ocorrência de infecção cruzada e da disseminação destas estirpes $^{(20)}$.

A detecção da resistência à oxacilina pela utilização de métodos fenotípicos apresenta-se problemática pela expressão heterogênea do gene mecA. Várias metodologias estão sendo desenvolvidas e outras modificadas para aumentar a detecção de isolados verdadeiramente resistentes à oxacilina. Entre elas, destacam-se o teste de disco difusão, o teste de triagem em ágar e o método de diluição em ágar para determinação da $\mathrm{CIM}^{(6)}$.

Em nosso estudo observou-se que os antimicrobianos mais ativos contra ORSA foram linezolide com $100 \%$ de sensibilidade, vancomicina $(100 \%)$, mupirocina (100\%) e telitromicina (100\%). A resistência das amostras de ORSA a cefoxetina foi
$100 \%$, seguida da gentamicina (57\%), tetraciclina (57\%) e ciprofloxacina (57\%).

Métodos moleculares para detecção de resistência à oxacilina, como a PCR para o gene $m e c A$, são mais sensíveis que os métodos fenotípicos e por essa razão são utilizados como padrão ouro para avaliação da sensibilidade e especificidade de outros métodos ${ }^{(6)}$.

Em nosso estudo foi possível observar que das cinco amostras dos recém-nascidos oxacilina resistentes, quatro delas foram portadoras do gene mecA. Destas, uma amostra foi de RN ao nascer, duas antes da alta hospitalar e uma amostra foi de RN com 15 dias de vida. Isto demonstra que estafilococos resistentes a oxacilina não pode mais ser considerado um patógeno relacionado exclusivamente às infecções em unidades de saúde, pois além de infectarem indivíduos sem fatores de risco aparente, essas cepas têm perfil de resistência e virulência peculiares.

É importante lembrar que isolados mecApositivos (ou PBP2a-positivos) devem ser relatados como resistentes à oxacilina. Porém, isolados mecAnegativos (ou PBP2a-negativos) devem ser relatados como sensíveis apenas se a CIM para oxacilina for $\leq$ $2 \mu \mathrm{g} / \mathrm{ml}$ devido à ocorrência, ainda que rara, de outros mecanismos de resistência (como super produção de betalactamases e presença de PBPs modificadas), além do mediado pelo mecA. Assim, 
isolados mecA-negativos (ou PBP2a-negativos), mas com CIM $\geq 4 \mu \mathrm{g} / \mathrm{ml}$, devem ser relatados como resistentes. Cepas com PBPs modificadas e as cepas hiperprodutoras de betalactamases costumam, em geral, ter resistência de menor grau ou até limítrofe, quando em comparação com a resistência das cepas mecA-positivas. Essas últimas, apesar de apresentarem com freqüência fenótipo heterogêneo, tendem a ter pelo menos uma subpopulação com resistência de alto grau$^{(11)}$.

\section{CONCLUSÃO}

A atenção à saúde é constantemente desafiada por infecções causadas por microrganismos altamente virulentos e capazes de desencadear surtos graves em todos os setores das instituições de saúde. Atualmente, o portador são tem sido considerado uma importante fonte de microrganismos, tornando-se, dessa forma, uma ameaça de propagação de infecções. Este estudo teve como objetivo trazer uma contribuição para a epidemiologia no que diz respeito ao carreamento de S. aureus entre recém-nascidos saudáveis, particularmente aqueles resistente a oxacilina.

A partir da população em estudo foi possível observar que $90 \%$ dos recém-nascidos foram carreadores de $S$. aureus, que $11,1 \%$ destes foram identificados como portadores de ORSA. Destarte, os profissionais de saúde precisam estar particularmente atentos para a identificação de carreadores de $S$. aureus; e como estão diretamente envolvidos no cuidado com clientes, devem tomar precauções para controlar e prevenir sua disseminação, ressaltando a importância da conscientização da necessidade de planejamento, implementação e avaliação de medidas direcionadas ao controle de $S$. aureus multirresistentes e, consequentemente, das estafilococcias.

\section{REFERÊNCIAS}

1. Von Eiff C, Bekcer K, Machka K, Stamer H, Peters

G. Nasal carriage as a source of staphylococcus aureus bacteremia. N Engl J Med. 2001;344(1):11-6. 2. Muder RR, Brennen C, Wagener MM, Vickers RM, Rihs JD, Hancock GA et al. Methicillin-resistant staphylococcal colonization and infection in a longterm care facility. Arch Intern Med.1991;114(2):10712.

3. Priya Behari MD, Janet Englund MD, Grace Alcasid MPH, Sylvia Garcia-Houchins CIC, Stephen Weber MD. Transmission Of Methicillin-Resistant Staphylococcus Aureus to Preterm Infants Through Breast Milk. Infect Control Hosp Epidemiol. 2004;9(25):778-80.

4. Novak FR, Da Silva AV, Hagler AN, Figueiredo AM. Contamination of expressed human breast milk with an epidemic multiresistant Staphylococcus aureus clone. J Med Microbiol. 2000;49(12):1109-17.
5. Lode HM. Clinical impact of antibiotic-resistant Gram-positive pathogens. Clin Microbiol Infect. 2009;15(3):212-7.

6. Hussain FM, Boyle-Vavra $S$, Daum RS. Community-acquired methicillin-resistant Staphylococcus aureus colonization in healthy children attending an outpatient pediatric clinic. Pediatr Infect Dis J. 2001;20(8):763-7.

7. Otter JA, Klein JL, Watts $T L$, Kearns AM, French GL. Identification and control of an outbreak of ciprofloxacin-susceptible MRSA-15 on a neonatal unit. J Hosp Infect. 2007;67(3):232-9.

8. Toda EN. Estudo da susceptibilidade do Staphylococcus aureus isolado no Laboratório Central da Santa Casa de São Paulo, no período de setembro/2000 a março/2002 [dissertation]. São Paulo: Faculdade de Ciências Médicas da Santa Casa de São Paulo; 2003. 106p.

9. Jain A, Agarwal A, Verma RK. Cefoxitin disc diffusion test for detection of meticillin-resistant staphylococci. J Med Microbiol. 2008;57(8):957-61.

10. Mimica MJ, Berezin EM, Carvalho RL, Mimica IM, Mimica LM, Safadi MA et al. Detection of methicillin resistance in Staphylococcus aureus isolated from pediatric patients: is the cefoxitin disk diffusion test accurate enough? Braz. j. infect. dis. 2007;11(4):415-7.

11. Jorgensen $\mathrm{JH}$. Selection criteria for an antimicrobial susceptibility testing system. J Clin Microbiol.1993;31(11):2841-4.

12. Mohanasoundaram KM, Lalitha MK. Comparison of phenotypic versus genotypic methods in the detection of methicillin resistance in Staphylococcus aureus. Indian J Med Res. 2008;127(1):78-84.

13. Vannuffel $P$, Gigi J, Ezzedine $H$, Vandercam $B$, Delmee M, Wauters G, Gala JL. Especific detection of methicillin-resistant taphylococcus species by multiplex PCR. J Clin Microbiol. 1995;33(11):286467.

14. Cimolai N. Staphylococcus aureus outbreaks among newborns: new frontiers in and old dilemma. Am J Perinatol. 2003;20(3):125-36.

15. Bousso A, Terra CM, Martins FRP, Vaz FAC. Infecção Hospitalar em Recém-Nascidos. Pediatria. 1995;17(1):10-37.

16. Lamaro-Cardoso J. Prevalência e tipagem molecular de estafilococos isolados de aspirados nasofaríngeos de crianças com infecções respiratórias agudas no município de Goiânia [dissertation]. Goiânia: Universidade Federal de Goiás; 2005.108p.

17. Loureiro MM, Moraes BA, Quadra MRR, Pinheiro GS, Suffys PN, Asensi MD. Molecular epidemiology of methicilin-resistant Staphylococcus aureus isolated from newborns in a hospital in Rio de Janeiro, Brazil. Mem Inst Oswaldo Cruz. 2000;95(6):777-82.

18. Clinical and Laboratory Standards Institute (CLSI). Performance standards for antimicrobial susceptibility testing, seventeenth informational 
supplement, document M100-S17. Wayne: CLSI;

2007.

19. Palos MAP. Staphylococcus aureus e Staphylococcus aureus meticilina resistentes (MRSA) em profisionais de saúde e as interfaces com as infecções nosocomiais [thesis]. Ribeirão Preto: Escola de Enfermagem/USP; 2006. 175p.

20. Neves MC, Rossi Júnior OD, Alves ECC, Lemos MVF. Detecção de genes de resistência antimicrobiana em cromossomos e plasmídeos de staphylococcus spp. Arq Inst Biol. 2007;74(3):20713.

Artigo recebido em 18.08.08.

Aprovado para publicação em 13.08.09.

Artigo publicado em 31.12.09. 